\title{
A Rede de Apoio Social e o Papel da Mulher na Geração de Ocupação e Renda no Meio Rural
}

\author{
Neuzeli Maria de Almeida Pinto ${ }^{1}$ \\ Programa de Pós-Graduação em Teoria e Pesquisa do Comportamento da Universidade \\ Federal do Pará, Belém, Brasil \\ Centro de Ciências Sociais Aplicadas da Universidade Estadual do Maranhão, \\ São Luis, Brasil \\ Fernando Augusto Ramos Pontes \\ Laboratório de Ecologia do Desenvolvimento da Universidade Federal do Pará, \\ Belém, Brasil \\ Simone Souza da Costa Silva \\ Núcleo de Teoria e Pesquisa do Comportamento da Universidade Federal do Pará, \\ Belém, Brasil
}

\begin{abstract}
Resumo
O objetivo deste estudo foi investigar a relação entre rede de apoio social e papeis desenvolvidos por mulheres que exercem a atividade da meliponicultura tendo em vista sua participação na manutenção das redes de apoio que garantem o exercício da atividade, e, consequentemente, a ocupação e renda para a sobrevivência de famílias em comunidades rurais do Maranhão. Participaram sete mulheres de duas comunidades integradas ao Projeto Abelhas Nativas (PAN), que visa o desenvolvimento da meliponicultura como atividade sustentável. Foram utilizadas entrevistas semiestruturadas, DC e o M5C, que permitiu avaliar a estrutura e função das redes de apoio social. Constatou-se uma intensa rede de apoio social mantida pelas mulheres presentes em todos os campos estudados. Verifica-se que a existência desta rede permite às mulheres a circulação em vários contextos, bem como a interação entre as pessoas de outros microssistemas de modo adaptado e com equilíbrio nas relações de poder, proporcionando a possibilidade de terem sucesso na execução da atividade da meliponicultura.
\end{abstract}

Palavras-chave: Família, divisão sexual do trabalho, rede de apoio social, meliponicultura, ocupação, renda.

\section{The Social Support Network and the Role of Women in Employment and Income Generation In Rural Areas}

\section{Abstract}

The aim of this study was to investigate the relationship between social support and papers developed by women who pursue beekeeping activity in order to maintain its share of the support networks that

1 Endereço para correspondência: Departamento de Ciências Sociais, Centro de Ciências Sociais Aplicadas, Universidade Estadual do Maranhão, Cidade Universitária Paulo VI, s/n, Tirirical, São Luis, MA, Brasil 65000000. Caixa-postal: 09. E-mail: neuzelialmeida@globo.com, farp1304@gmail.com e symon.ufpa@gmail.com Apoio financeiro: Universidade Estadual do Maranhão (UEMA)/ Conselho Nacional de Desenvolvimento Científico e Tecnológico (CNPq)/ Coordenação de Aperfeiçoamento de Pessoal de Nível Superior (CAPES). 
guarantee the exercise of the activity, and consequently the occupation and income to the survival of families in rural communities of Maranhão. Participants were seven women in two communities integrated with Project Native Bees (PAN), which aims at the development of beekeeping as a sustainable activity. Semi-structured interviews were used, DC and M5C, which allowed to evaluate the structure and function of social support networks. There was a strong social support network for women maintained a presence in all fields studied. It appears that the existence of this network allows women to the movement in various contexts, as well as the interaction between people of other microsystems so adapted and balance in power relations, providing the ability to succeed in performing the activity of beekeeping.

Keywords: Family, sexual division of labor, social support network, beekeeping, occupation, income.

\section{La Red de Apoyo Social y el Papel de la Mujer en el Empleo y la Generación de Ingresos en las Zonas Rurales}

\section{Resumen}

El objetivo de este estúdio fue investigar la relación entre el apoyo social y los documentos elaborados por las mujeres que ejercen la actividad apícola com el fin de mantener su cuota de las redes de apoyo que garanticen el ejercicio de la actividad y, en consecuencia, la ocupación y los ingresos para la supervivencia de las famílias en las comunidades rurales de Maranhão. Los participantes fueron siete mujeres de dos comunidades integradas com las abejas nativas de proyecto (PAN), cuyo objetivo es el desarrollo de la apicultura como una actividad sostenible. Semi-estructuradas se utilizan, DC y M5C, lo que permitió evaluar la estructura y función de las redes de apoyo social. Hubo una fuerte red de apoyo social para las mujeres mantienen una presencia en todos los âmbitos estudiados. Parece que la existencia de esta red permite a las mujeres del movimiento en diversos contextos, así como la interacción entre personas de microsistemas otros para adaptarse y equilíbrio en las relaciones de poder, que proporciona la capacidad de tener êxito en el desempeño de la actividad de la apicultura.

Palabras clave: Familia, división sexual del trabajo, red de apoyo social, apicultura, ocupación, renta.

Pesquisas desenvolvidas na atualidade demonstram que as mulheres exercem papeis importantes no âmbito familiar. Elas são as principais responsáveis pela organização doméstica, além de desenvolverem atividades remuneradas que lhes coloca como mantenedoras financeiras do lar, mesmo acumulando a maior responsabilidade pelo trabalho doméstico e educação dos filhos (F. S. Brito, 2008; Fleck \& Wagner, 2003; M. dos S. Macedo, 2001). Fatores como a necessidade socioeconômica e a própria consolidação da mulher no mercado de trabalho são apontados como influentes da emancipação da mulher na sociedade moderna. Estes fatores podem contribuir para a circulação das mulheres em vários contextos, bem como a interação entre as pessoas de outros microssistemas. Do ambiente familiar para o contexto do trabalho, há inúmeras mudanças na vida destas mulheres e nas suas redes de apoio social. Este movimento no espaço ecológico com consequentes mudanças de papeis é denominado por Bronfenbrenner (1979/1996) de transição ecológica.

Além de toda a dinâmica de funcionamento interno da família que a mulher vivencia, vários outros sistemas fora dela exercem importante influência em suas interações com seu contexto, e, mais especificamente, nas atividades de ocupação e renda. Dentre esses sistemas, podem se destacar o local de trabalho, a vizinhança, as associações comunitárias e a própria comunidade. Essas interações mantidas pelas mulheres implicam compartilhar propósitos e valores comungados pelos demais integrantes, cujas conexões destinam-se a permitir apoio mútuo (Marteleto \& Silva, 2004), rede de relações que apontam 
algum tipo de mudança concreta na vida destas mulheres, no coletivo e nas organizações envolvidas.

As redes sociais são depositárias de identidade individual e grupal, fonte de retroalimentação e conhecimento social. Por meio do intercâmbio dinâmico entre seus integrantes e entre eles e outros grupos sociais, a rede social possibilita a utilização de recursos que beneficiam o desenvolvimento dos membros da família e da comunidade (Atneave \& Ross, 1982; Elkaim, 1989; Meneses, 2007). Portanto, é possível definir redes sociais como um sistema aberto em permanente construção no cotidiano a partir das relações com as pessoas ou grupos sociais. É um conjunto de relações que geram reconhecimento, sentimento de identidade, competência e ação (Meneses \& Sarriera, 2005).

Algumas funções para as redes sociais foram identificadas por Sluzki (1996), tais como companhia social, apoio emocional, guia cognitivo e conselho, regulação social, ajuda material e de serviços e acesso a novos contatos. As funções das redes sociais estabelecem-se, portanto, na interação entre os diversos membros da família e da comunidade que compõem. Argumenta-se, então, que as participações nas redes possibilitam conhecer outros e, consequentemente, as probabilidades de exercer e solicitar as funções sociais. Essa discussão é aprofundada por Meneses (2007) que diferencia os conceitos de rede social, apoio social e rede de apoio. Assim, assinala que as redes sociais fazem referência às características estruturais das relações sociais; o apoio social refere-se às funções que presta essa rede, ou seja, o efeito sobre o bem-estar das pessoas. Entende, pois a rede de apoio como o conjunto de relações que desempenham funções de apoio e pode contribuir para a manutenção e sobrevivência dos membros da família e da comunidade.

A rede de apoio social é considerada uma importante dimensão do desenvolvimento, constituindo uma interface entre o sujeito e o sistema social, do qual os membros da família e os grupos de trabalho fazem parte. Em que é relacionado à percepção que a pessoa tem de seu contexto, como se orienta nele, suas estratégias e competências para estabelecer vínculos, e com os recursos que este lhe oferece, como proteção e sustentabilidade, frente às situações desafiadoras que se apresentam (R. Brito \& Koller, 1999). Dessa forma, a rede de apoio social contribui também para o aumento da competência individual, que reforça a autoimagem e a autoeficácia necessária para alcançar objetivos (Garmezy \& Masten, 1994). Ademais, redes de apoio baseadas em alianças de ajuda econômica e de trabalho, podem ser marcadas por padrões de gênero que delimitam os ambientes das atividades cotidianas, definem o status ocupado na família e condicionam a formação de vínculos na rede social (S. S. C. Silva, Pontes, Lima, \& BucherMaluschke, 2010).

Dentre as estratégias das famílias destacamse aquelas desenvolvidas pelas mulheres ao ingressar no mercado de trabalho. Tal fato requer a criação de redes de apoio social para auxiliar a família a se adaptar às possíveis mudanças, como a redefinição da divisão sexual do trabalho, estabelecendo novas formas de exercício da autoridade na família (Carloto \& Mariano, 2010; Romanelli, 1986). Apesar da significativa ocupação da mulher no mercado de trabalho, a responsabilidade que sempre lhe foi atribuída quanto aos afazeres domésticos e à educação dos filhos não diminuiu (Bruschini, 1994, 2007; Oliveira, 1990). A contribuição da mulher para suprir as necessidades das famílias de baixa renda ocorre por meio das atividades do trabalho doméstico, da produção de valores de uso e da atividade profissional remunerada, no mercado formal ou informal. No entanto, em função da baixa qualificação profissional das mulheres das classes populares e da desvalorização geral do trabalho feminino, a remuneração que elas podem obter é, de modo geral, pequena. Além disso, as atividades remuneradas, muitas vezes, são realizadas simultaneamente com as tarefas domésticas.

Dados da literatura referente às mulheres trabalhadoras indicam que, para superar as adversidades do cotidiano familiar e da comunidade, elas atuam como articuladoras e mantenedoras das relações com vizinhos e parentes, o que revela uma grande capacidade de organização e articulação das estratégias de sobrevivência (Durham, 1973; Fausto-Neto, 1982). Dentre essas articulações por elas elaboradas, Fonseca 
(1987) verificou uma forte relação de solidariedade e apoio entre parentes consanguíneos. Em troca desse apoio, realizam tarefas domésticas e trabalhos informais que beneficiam os parentes "aliados", podendo também ajudá-los financeiramente. No geral, a condição social e o modo de sobrevivência ativam uma rede de apoio. Compreender a relação entre modo de sobrevivência e rede de apoio desenvolvida implica entender mecanismos relacionais de caráter sociocultural (Szymanski, 2002).

Segundo Szymanski (2002), a grande variedade de estruturas familiares atuais, faz com que se mude o foco da estrutura da família nuclear, como modelo de organização, para considerar novas questões em relação à convivência entre as pessoas na família, sua relação com a comunidade mais próxima e com a sociedade mais ampla. Em uma psicologia sistêmica e na área da psicologia da família, o conhecimento das redes de suporte sociais e das diversas estratégias desenvolvidas por essas mulheres para garantir as múltiplas tarefas a elas atribuídas, possibilita o entendimento da diversidade de inter-relação entre sistemas envolvidos ao familiar e nos diferentes papeis desenvolvidos por seus membros.

Contudo, a necessidade de articulação entre vida doméstica e trabalho pode ser geradora de estresse. Tal aspecto se amplia visto que o estresse dificulta o exercício do seu papel de mãe e educadora, pois em tais arranjos as mulheres continuam a ser as principais cuidadoras da família. Desse modo, a rede de apoio assume um papel fundamental na articulação entre a vida doméstica e o trabalho, possibilitando o exercício do papel de mãe de forma mais eficiente.

Das mais variadas formas de sobrevivência desenvolvidas pelas famílias de baixa renda, a criação de abelha indígena em comunidades rurais no Nordeste do Maranhão possui uma característica bastante peculiar, pois são as mulheres que estão diretamente e intensivamente envolvidas na atividade da meliponicultura (criação de abelhas sem ferrão) e essa atividade é desenvolvida ao redor da própria residência. Desse modo, há uma conjugação das atividades de ocupação e renda em conjunto com as tarefas domésticas e familiares.
Para o desenvolvimento das atividades relacionadas ao trabalho e da família é possível que essas necessitem integrar-se em redes de apoio social mais ampla de ajuda mútua, envolvendo parentes e vizinhos. A integração das famílias de classes populares nas "redes horizontais" de troca de favores e solidariedade tem a função de assegurar socialmente essas famílias. As relações que se integram e resultam nas relações da rede de apoio, constituem desafios que se concretizam no cotidiano da família. A interconexão entre rede de apoio, modo de sobrevivência, e a questão de gênero apresenta um colorido peculiar nessa forma de ocupação e renda.

Torna-se importante compreender como se estrutura e funciona a rede de apoio nos diferentes contextos. Ademais a construção das redes de apoio social pelas mulheres pode representar um fator relevante para o desenvolvimento do trabalho da meliponicultura, consequente melhoria da qualidade de vida dessas famílias, nas relações familiares e no desenvolvimento de papeis de gênero. É nesse sentido que este trabalho investigou a relação entre rede de apoio social e papeis desenvolvidos por mulheres que exercem essa atividade, tendo em vista sua participação na manutenção das redes de apoio que garantem o exercício da meliponicultura, e consequentemente, a ocupação e renda para a sobrevivência de famílias em comunidades rurais do Maranhão.

\section{Método}

\section{Participantes}

Participaram da pesquisa 07 mulheres meliponicultoras, sendo quatro delas da comunidade de Preazinho e 03 da comunidade de Marajá, no Município de Belágua/MA (Tabela 1). As famílias das comunidades estudadas fazem parte do Projeto de Abelhas Nativas - PAN, facilitador para a mobilização das famílias participantes. Todas as mulheres que participaram da pesquisa são casadas, em união estável, e todas as famílias são nucleares, exceto uma família em que o neto mora com os avós, sendo que duas delas são casadas no civil e religioso, três somente no religioso, uma é casada somente no civil e uma sem registro no cartório e no religioso. 
Tabela 1

Relação das Mulheres Meliponicultoras, Filhos, Agregados e Meliponários por Comunidade

\begin{tabular}{lcccc}
\hline Comunidade & $\begin{array}{c}\text { Mulheres } \\
\text { Meliponicultoras* }\end{array}$ & $\mathrm{N}^{\circ}$ de filhos & $\begin{array}{c}\mathrm{N}^{\circ} \text { de agregados } \\
\text { familiar }\end{array}$ & $\begin{array}{c}\mathrm{N}^{\circ} \text { Meliponário } \\
\text { comunitário }\end{array}$ \\
\hline \multirow{3}{*}{ Preazinho } & Cláudia & 5 & 1 (neto) & \\
& Maria das Dores & 1 & - & 1 \\
Andrea & 2 & - & \\
Marajá & Francisca & 3 & - & 1 \\
& Adriana & 5 & - & \\
\hline
\end{tabular}

Nota. * Por questões éticas os nomes utilizados são fictícios.

\section{Ambiente: Comunidades}

O trabalho foi realizado na Região Nordeste Maranhense. Esta região está localizada na fronteira do semiárido, numa área de contato de três grandes biomas, compreendidos no cerrado, caatinga e Amazônia, conferindo à mesma uma feição fitogeográfica particular, constituindo uma porta para o processo de desertificação no sentido Leste-Oeste. Esta região (Nordeste Maranhense) possui um extremo grau de pobreza, com uma renda per capita de $\mathrm{R} \$ 54,90$, sendo que $56 \%$ da população é analfabeta e $59 \%$ vive no campo, com uma carência extrema de serviços de atendimento básico, como saúde e educação. Esses ingredientes conferem à região um IDH (Índice de Desenvolvimento Humano) de 0,495, uns dos menores do Brasil, estando abaixo da média dos municípios do Estado (Instituto Brasileiro de Geografia e Estatística [IBGE], 2000).

Em razão das suas características sociais, econômicas e ambientais, a população do Nordeste Maranhense apresenta um dos maiores contingentes extrativistas do Brasil. Durante as últimas décadas, a população dessa região vem enfrentando diversos problemas relacionados à falta da terra. Muitos agricultores, quando a possuem, tornam-se pequenos proprietários, geralmente em solo de baixa fertilidade, não garantindo uma produção sustentável para a família (Associação Maranhense para a Conservação da Natureza [AMAVIDA], 2005).
As comunidades do Preazinho e de Marajá têm cerca de 30 famílias. Com um total de 240 moradores, sendo que 120 estão em idade escolar. A escola local só ensina até a $4^{\mathrm{a}}$ série do Ensino Fundamental e atualmente foi criado um curso de alfabetização no período da noite para os adultos das comunidades. No momento da pesquisa a escolaridade média era inferior a dois anos de estudo, correspondente ao ensino fundamental incompleto. As escolas das comunidades funcionam em casas de pau a pique ${ }^{2}$ e são cobertas de palha. Não há posto de saúde, mas há regularidade na visita dos agentes de saúde. Não há sistema de saneamento básico de água e esgoto e tratamento de lixo. A maioria das famílias das comunidades possui geladeira, televisão e antena parabólica e muitas delas usam o fogão a lenha.

As famílias participantes já realizam a atividade da meliponicultura há décadas; a atividade foi passada de geração a geração de forma rústica. Atualmente desenvolvem a atividade de uma forma racional. As mulheres da comunidade tra-

2 Pau a pique - é uma técnica construtiva antiga que consistia no entrelaçamento de madeiras verticais fixadas no solo, com vigas horizontais, geralmente de bambu amarradas entre si por cipós, dando origem a um grande painel perfurado que, após ter os vãos preenchidos com barro, transformava-se em parede (Ferraz, 1992). 
balham no meliponário regularmente na limpeza de todo o ambiente, alimentam as colmeias que estão fracas e fazem revisão das caixas, verificando as que estão fortes ou fracas. Essas atividades são realizadas semanalmente, onde é formado um mutirão das famílias envolvidas no projeto.

\section{Instrumentos}

A coleta de dados foi realizada por meio da aplicação de uma entrevista semiestruturada, do Mapa dos Cinco Campos (M5C) e diário de campo (DC).

A entrevista semiestruturada consistiu na identificação, por meio dos dados pessoais, rede de parentesco no local, perfil familiar, condições de vida, e concepções pessoais sobre papeis no trabalho, na comunidade e na família, e relação de apoio e conflito: família, parentes vizinhos e amigos, grupo de trabalho do meliponário e Associação do Projeto Abelhas Nativas (APAN). As questões foram lidas pela pesquisadora e as respostas assim como os comentários das mulheres foram gravadas para transcrição posterior. Os conteúdos foram analisados seguindo os temas definidos a priori, no entanto, relatos espontâneos das mulheres foram registrados e analisados.

O M5C foi utilizado com o objetivo de identificar a estrutura (quantidade dos vínculos estabelecidos na rede) e a função (qualidade dos vínculos) da rede de apoio das mulheres na execução das atividades ligado aos contextos em que participam (Samuelsson, Thernlund, \& Ringstrom, 1996, adaptado por Hoppe, 1998).

O M5C utilizado consistiu em um quadro de banner com medidas de $60 \times 90 \mathrm{~cm}$. Nesse quadro, estão desenhados seis círculos concêntricos verdes, que vão perdendo a intensidade da cor à medida que os círculos vão se distanciando do centro, caracterizando o enfraquecimento das relações. Esses círculos representam os níveis de proximidade da participante, o qual se encontra ao centro; e estão subdivididos em cinco campos: Família, APAN, Amigos/Vizinhos/ Parentes, Grupo de Trabalho do Meliponário e Outros Locais. Para fins de representar adultos, adolescentes e crianças, foram utilizados recor- tes esquemáticos de figuras de ambos os sexos, e de tamanhos diferentes. Para fins de identificar o grau de satisfação e insatisfação existiam figuras com cores diferentes disponíveis: amarelo para satisfação nas relações, e vermelho insatisfeito nas relações ou que mantém algo como conflito e/ou rompimento.

As participantes foram solicitadas a colocar as pessoas que fazem parte da sua vida em cada um dos campos, sendo que quanto mais satisfatório o relacionamento é percebido, mais próximo do centro a pessoa será colocada $\left(1^{\circ}\right.$ e $2^{\circ}$ nível), usando as figuras amarelas. A participante pode colocar os contatos que classifica como um relacionamento mais distante e/ou insatisfatório no $3^{\circ}$ e $4^{\circ}$ níveis. No $5^{\circ}$ nível, o mais externo, foi orientado que ela indicasse os contatos com conflitos e rompimento das relações, sendo usadas as figuras vermelhas. À medida que esses relatos eram feitos pelos participantes, a pesquisadora registrava na ficha controle os contatos citados como conflituosos, os rompimentos satisfatórios e insatisfatórios.

Em cada círculo, as participantes indicavam as pessoas importantes ("que mais goste"), assim como aquelas com quem mantêm um mau relacionamento ("que não goste"). É solicitado, ainda, que a participante identifique a existência de conflito (brigas) e rompimentos nas relações. A pesquisadora registrou na ficha controle assinalada pelo símbolo $\uparrow$ a existência de conflito (brigas), e assinalado rompimento de relações entre a participante e alguma das pessoas representadas (pessoa com quem "não se dá") com o símbolo $\ddagger$ e, ainda, em cada campo, sua satisfação (gosta) ou insatisfação (não gosta) nos relacionamentos envolvidos pelos símbolos "S" e "I", respectivamente. Ressalta-se que, nesta pesquisa, o campo Família considera apenas os coabitantes da mesma residência. E o campo Parentes/Vizinhos/Amigos, a maioria deles são aparentadas e moram na mesma comunidade.

Além disso, foi utilizado o DC a fim de obter e registrar aspectos ecológicos pertinentes às análises, registrando os dados recolhidos susceptíveis de serem interpretados. Neste sentido, o diário de campo é uma ferramenta que permite sistematizar as experiências para posteriormen- 
te analisar os resultados (Rubio \& Devillard, 2001). A pesquisadora realizou uma inserção no contexto das rotinas dos participantes para se aproximar e compreender seu universo sociocultural. Após cada visita às famílias, as observações eram registras em DC: descrições das pessoas, objetos, lugares, acontecimentos, atividades e conversas vivenciadas durante a coleta de dados; bem como estratégias e reflexões do pesquisador.

\section{Procedimento da Coleta e Considerações Éticas}

Esse trabalho constitui uma parte de uma projeto maior relativo a proposta de Tese de doutoramento da primeira autora. Nesse sentido, inicialmente foi feito o contato com a comunidade e por negociação com as lideranças foi exposta a proposta do trabalho. Na sequência foi elaborado o projeto e submetido ao Comitê de Ética em Pesquisa em Seres Humanos da Universidade Federal do Pará (CEP-ICS/UFPA, parecer $n^{\circ}$ 130/10). Para cada família participante foi solicitada uma permissão por escrito do participante (entrega do TCLE) para a aplicação das entrevistas semiestruturada e do M5C, além do uso do DC, esclarecendo que os dados seriam confidenciais e que o entrevistado não seria identificado. Para isto, os nomes das mulheres usados na análise da pesquisa foram fictícios com o objetivo de manter a privacidade das participantes. Foram feitas então visitas às comunidades onde inicialmente, foi aplicado um piloto visando a constatar possíveis inadequações do roteiro de entrevista, assim como problemas e dificuldades na relação com os informantes e a linguagem utilizada.

Posteriormente foi realizada a aplicação da entrevista semiestruturada e do M5C. A coleta de dados ocorreu na casa das famílias. Os instrumentos foram aplicados individualmente, em uma única sessão, para cada participante, com uma duração média de 50 minutos.

\section{Procedimentos de Análise}

Com os dados da entrevista semiestruturada foram feitas analises de natureza qualitativa de conteúdo. Tal procedimento teve como objetivo relacionar aspectos socioeconômicos das famílias com a sua rede de parentesco no local e a percepção das respondentes da rede de apoio existente.

Os dados do DC foram analisados a partir da sistematização das experiências das participantes para fins de captar a percepção sobre a rede de apoio, seu trabalho no meliponário e a divisão de tarefas na família. A análise do M5C segue os procedimentos descritos por Siqueira, Betts e Dell'Aglio (2006). A estrutura das redes foi avaliada por meio do (a) número total de pessoas por nível de proximidade; (b) por campo; e (c) em toda a rede. A qualidade dos vínculos (função) foi avaliada a partir da (a) colocação das pessoas nos círculos adjacentes ao centro, que representam os níveis de proximidade: o primeiro e o segundo níveis correspondem às relações mais próximas; o terceiro e o quarto níveis correspondem às relações mais distantes; e o último nível (periférico, em vermelho) representa os contatos insatisfatórios e com rompimento; (b) média das relações caracterizadas por conflitos e rompimentos; (c) qualidade da relação; e (d) fator de proximidade por campo e total.

O fator de proximidade é uma variável que representa o grau de vinculação das participantes com o número de pessoas citadas nos campos, sendo medido por meio da localização dessas pessoas em relação ao círculo central, no qual está a participante. Para o cálculo desse escore, o número de pessoas colocadas no primeiro círculo é multiplicado por oito, no segundo nível por quatro, no terceiro nível por dois, no quarto nível por um, e no quinto nível por zero. $\mathrm{O}$ somatório desse cálculo é dividido pelo número total de pessoas citadas no campo, para a média de proximidade no campo, ou pelo número total de pessoas citadas no M5C, para a média de proximidade do mapa.

Os dados coletados através da entrevista semiestruturada e do DC foram transcritas e analisadas qualitativamente como uma forma de complementação dos dados obtidos através do M5C. 


\section{Resultados}

Verifica-se por intermédio das observações apontadas no diário de campo que em relação à caracterização da constituição das famílias estudadas, que somente duas destas mulheres são recasadas e tem filhos da união anterior que moram com a família. Além disso, elas criam os netos que são deixados na residência durante o dia, ou moram em tempo integral. Os filhos casados moram na comunidade. A partir da montagem do mapa genealógico das famílias participantes foi possível verificar que a maioria dos seus moradores tem algum grau de parentesco entre si. As duas comunidades estudadas são compostas por uma única rede de parentesco em cada comunidade, com famílias que compõem uma rede multigeracional, incluindo avós, pais, tios primos, filhos e netos de uma mesma rede familiar.

No referente à ocupação das mulheres participantes, a partir dos dados da entrevista semiestruturada identificou-se que todas as mulheres participantes trabalham na lavoura e no meliponário. Suas atividades no meliponário são em essência a limpeza e a colheita do mel, já os homens são responsáveis pela captura dos ninhos, a transferência e divisão das colmeias. Adicionalmente, as mulheres são responsáveis diretas pelas atividades domésticas. A partir dos relatos do DC foi possível identificar que elas consideram as atividades do meliponário como "leves".

"O trabalho da gente no meliponário é mais leve, porque temos que dá conta do serviço da casa também. Os homens cuidam do serviço mais pesado, como tirar palha para fazer a cobertura do meliponário" (Denise, Junho/2010, Marajá).

No referente à concepção que as mulheres têm desse papel pode-se perceber que no relato das entrevistadas acreditam que o seu trabalho no meliponário e na lavoura é considerado como uma "ajuda" e acreditam que a função da mulher deve ser cuidar da casa, e a função do homem é o trabalho na roça. Como por exemplo, declara Denise:

"O homem tem que colocar a comida dentro de casa né? E a gente trabalha dentro de casa cuidando dos filhos e da casa" (Claudia, Julho/2010, Preazinho).
"A gente ajuda com o serviço da roça, mas a nossa obrigação é cuidar da casa, dos filhos e o homem tem que sair para trabalhar todos os dias e sustentar a familia" (Denise, Junho/2010, Marajá).

Um aspecto curioso da fala acima é a concepção de que o cuidado do meliponário é quase que uma extensão das "tarefas do lar". Contudo, a percepção das mulheres sobre a contribuição no orçamento e a relação de poder na família da maioria das participantes é que a mulher que trabalha exerce maior participação nas decisões familiares. É o que demonstra as falas:

"A gente que trabalha tem mais opinião dentro de casa, somos mais ouvidas. A nossa ajuda é importante para sustentar a familia, senão tivesse esse pouco meu que entra, seria muito dificil" (Andrea, Junho/2010, Marajá).

"Ele entrega o dinheiro para mim, eu sou mais controlada e sei o que precisa aqui dentro de casa" (Adriana, Junho/2010, Marajá).

Desse, modo, o seu papel nos cuidados do meliponário e na contribuição da renda pode estar influenciando na partilha de poder familiar, cinco participantes citaram que têm controle sobre o rendimento da família e nas decisões de consumo; o orçamento familiar é entregue a elas, com a responsabilidade de fazer a destinação das despesas e dos gastos da família.

No referente à educação dos filhos e a conflitos entre o casal, as entrevistas semiestruturadas indicam que quatro das mulheres participantes acreditam ainda que o trabalho que elas desenvolvem na lavoura e no meliponário não prejudica a educação dos filhos e o cuidado com a casa, pois os filhos permanecem um período na escola e no outro estão sempre pelos arredores das casas; e os vizinhos, que na sua maioria são parentes próximos, ajudam com o cuidado dos menores. Além disso, elas declaram que a dedicação das mulheres ao trabalho remunerado, lavoura e meliponário não acarreta nenhum tipo de conflito entre o casal, pois o trabalho tem a finalidade de ajudar no orçamento familiar.

Em relação ao $\mathrm{M} 5 \mathrm{C}$, foram executadas, ainda, análises descritivas e inferenciais. Foram levantados o número de contatos satisfatórios, 
insatisfatórios, conflitos e rompimentos, e também o grau de proximidade. A Figura 1 a seguir mostra o exemplo da aplicação do M5C com as adaptações para a presente pesquisa:

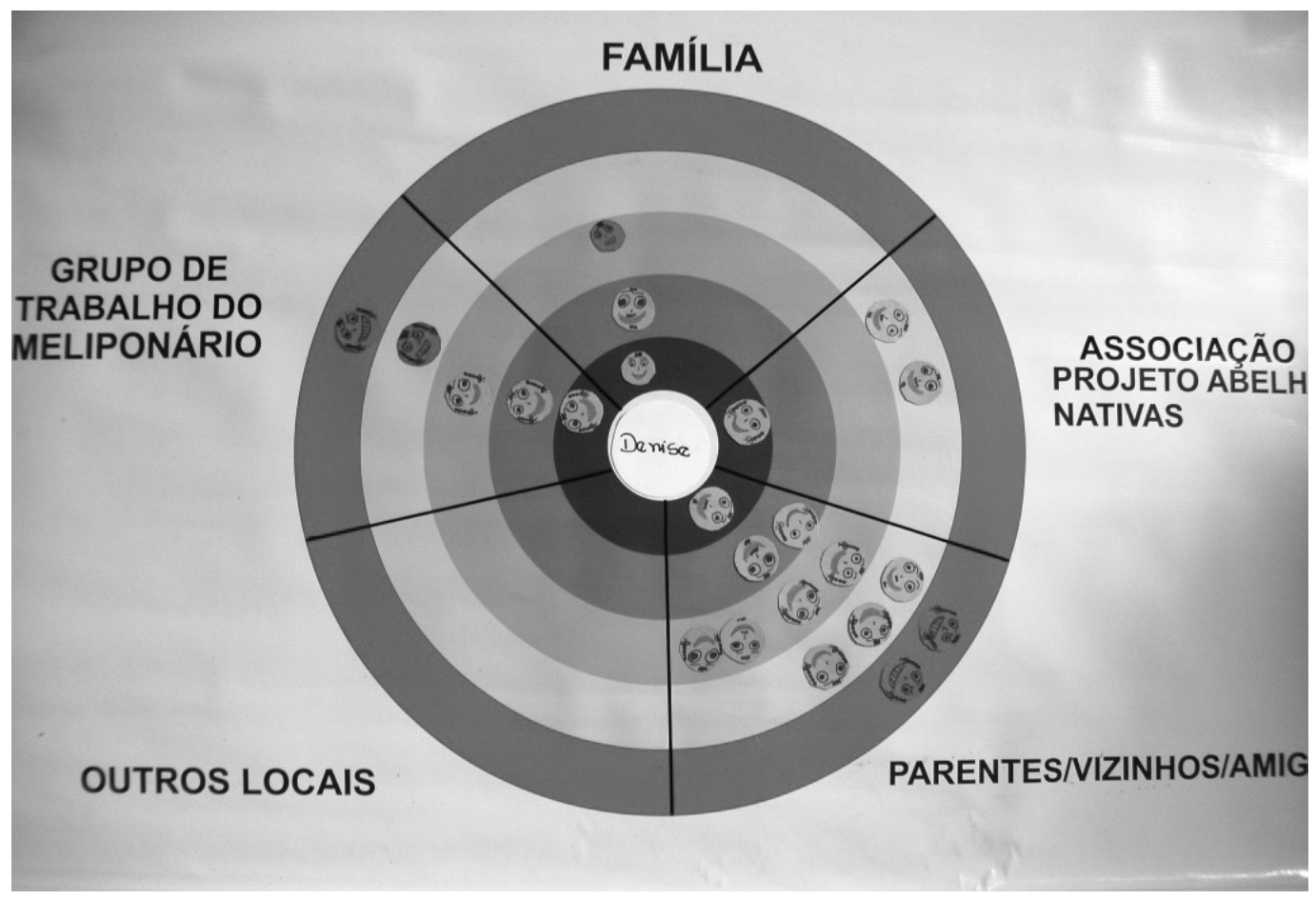

Figura 1. Exemplo do M5C (Samuelsson et al., 1996).

$\mathrm{Na}$ análise por níveis de proximidade, foi encontrada uma média maior $(10,29)$ de contatos no primeiro nível em relação aos contatos do segundo $(5,71)$; contatos no terceiro $(3,71) \mathrm{e}$ os contatos do quarto nível $(2,42)$. Apesar de o campo Grupo de Trabalho do meliponário apresentar um maior número de contatos, comumente, os dados mostram também que esse campo apresenta um menor nível de proximidade (Tabela 2).

Tabela 2

Frequência Total de Contatos por Campo e por Nível de Proximidade

\begin{tabular}{lccccc}
\hline \multirow{2}{*}{ Campos } & \multicolumn{5}{c}{ Nível } \\
\cline { 2 - 6 } & $F$ & $M$ & & $F$ & $M$ \\
\hline Família & 33 & 4,71 & $1^{\circ}$ & 72 & 10,29 \\
Parentes/Vizinhos/Amigos & 55 & 7,85 & $2^{\text {o }}$ & 40 & 5,71 \\
Grupo de Trabalho do Meliponário & 56 & 8 & $3^{\circ}$ & 26 & 3,71 \\
APAN & 16 & 2,29 & $4^{\circ}$ & 17 & 2,42 \\
Outros locais & 5 & 0,71 & $5^{\circ}$ & 9 & 1,29 \\
Mapa & 165 & 23,42 & & & \\
\hline
\end{tabular}

Em relação à estrutura das redes de apoio, as participantes mencionaram 155 contatos satisfatórios e 09 contatos insatisfatórios, totalizando
164 pessoas, com média total de 23,43 contatos. Os resultados do M5C mostraram o campo Grupo de Trabalho no Meliponário como o de 
maior número de contatos, seguido pelo campo Parentes/Vizinhos/Amigos, composto particularmente por membros da família, e a Família, que apresentou menor número de contatos, uma vez que foram consideradas apenas coabitantes como participantes. O campo Outros Locais apresentou o menor número de contatos, sendo citado por apenas duas participantes. O campo APAN apresentou um pequeno número de contatos, é possível que esse resultado seja devido à recente criação da Associação, o novo contexto pode apresentar vínculos que ainda estão sendo estruturados, Além disso, uma maior articulação pode ser prejudicada pela dificuldade que as mulheres das comunidades encontram para se inserirem em movimentos e eventos da associação que ocorrem fora da comunidade, como pode ser verificado na fala da Claudia:

"Aqui é muito dificil de a gente participar das reuniões da associação, dos cursos, porque é dificil para as mulheres ir para Urbano Santos, é um dia inteiro, e temos o serviço da casa, os filhos para olhar, não dá para ir não" (Claudia, Julho/2010, Preazinho).

"Quem vai para as reuniões e faz os cursos de capacitação são os homens, ai eles ensinam a gente aqui".

No entanto, quatro das mulheres participantes estão cursando o ensino fundamental noturno da comunidade, e segundo relatos na entrevista semiestruturada, elas veem na alfabetização a possibilidade de uma maior atuação na associação e de qualificação na criação de abelhas e em outros trabalhos. A participação na associação pode estar influenciando em novas perspectivas de vida, como pode ser verificado abaixo na fala de Antônia:

"É difícil para nós fazer os cursos de capacitação na associação, a maioria não sabe escrever, mas agora muitas estão frequentando a escola noturna, vai melhorar para a gente, até para arrumar outros trabalhos" (Antônia, Junho/2010, Marajá).

No que se refere à funcionalidade, ou seja, à qualidade das relações estabelecidas na rede de apoio social das participantes, as análises das médias do total dos contatos satisfatórios e insatisfatórios indicam uma diferença significativa nos campos estudados. Sendo a média de contatos satisfatórios no campo de Parentes/ Amigos/ Vizinhos maior $(1,14)$, seguido pelo campo do Grupo de Trabalho no Meliponário $(6,71)$ e a Família $(3,71)$, a APAN $(2,14)$ e por fim Outros Locais $(0,71)$. Quanto aos contatos insatisfatórios, apresentam uma menor média comparado aos contatos satisfatórios, a média no campo de Parentes/Amigos/Vizinhos foi de contatos $(0,71)$, o campo de Grupo de Trabalho no Meliponário $(1,28)$, e a Família $(1)$, a $\operatorname{APAN}(0,14)$, e por fim Outros Locais o Grupo, conforme a Tabela 3.

\section{Tabela 3}

Frequência e Médias dos Contatos Satisfatórios e Insatisfatórios por Campo

\begin{tabular}{lcccc}
\hline \multirow{2}{*}{ Campos } & \multicolumn{2}{c}{ Contato satisfatório } & \multicolumn{2}{c}{ Contato insatisfatório } \\
\cline { 2 - 5 } & $F$ & $M$ & $F$ & $M$ \\
\hline Família & 26 & 3,71 & 7 & 1 \\
Parentes/ Vizinhos/ Amigos & 50 & 1,14 & 5 & 0,71 \\
Grupo de Trabalho do Meliponário & 47 & 6,71 & 9 & 1,28 \\
APAN & 15 & 2,14 & 1 & 0,14 \\
Outros locais & 5 & 0,71 & 0 & 0 \\
Mapa & 143 & 20,42 & 22 & 3,14 \\
\hline
\end{tabular}

Pode-se identificar a relação de parceria entre as famílias no trabalho no meliponário. Apesar de haver uma divisão das colmeias por famí- lias e de ocorrer eventuais conflitos, o cuidado e o manejo com todas as colmeias ocorrem de forma conjunta, bem como a divisão da produção 
também é dividida com todas as famílias de forma igualitária, independente de a produção ter ocorrido de forma desigual entre as colmeias das várias famílias. Observa na fala de Francisca:

"Aqui todo mundo se ajuda, as famílias trabalham em conjunto. Mesmo as colmeias sendo dividido, cada um têm a sua, a gente vai lá e cuida igual e na hora de tirar e vender o mel é partido para todo mundo, ou vê o que tem que comprar para o meliponário, tudo é decidido em conjunto. Pode haver alguma desavença, porque tem gente que falta, não ajuda muito, mas lá estamos todos juntos, os filhos, maridos, vizinhos, parentes" (Francisca, Julho/2010, Preazinho).

Ainda quanto à funcionalidade da rede de apoio das mulheres das comunidades considera-se importante analisar a qualidade das relações desses com suas figuras parentais, em que as relações com alguns membros são mais intensas, o que pode ser observado nas redes de apoio um mesmo membro presente em mais de um campo. Os 26 filhos e sete maridos das famílias estudadas foram citados repetidas vezes no campo da
Família, no Grupo do Trabalho no Meliponário e Outros Locais. Assim, foram levantadas a frequência e a localização dos maridos e filhos no M5C. De acordo com a Tabela 4, os maridos foram citados no nível mais próximo ao centro repetidas vezes em vários campos, onde estão as pessoas cujos contatos são mais satisfatórios. Além disso, vale destacar que apenas uma participante citou o marido no quinto nível, nível das relações insatisfatórias. Entretanto, os filhos quase a metade foi citada no primeiro nível (46,15\%), e no segundo nível essa percentagem é ainda menor (26,92\%), seguindo no terceiro nível $(19,23 \%)$, no quarto nível $(11,38 \%)$ e no quinto nível $(3,84 \%)$. Na Tabela 4 apresentam-se também os campos onde os maridos e filhos são citados repetidas vezes. Na Tabela 4 todos os maridos e filhos são citados no campo da Família e menos da metade dos maridos são citados também no campo do Grupo de Trabalho do Meliponário (28,57\%) e no campo de Outros Locais $(28,57 \%)$. Os filhos também são citados no Grupo de Trabalho do Meliponário, mas com uma menor porcentagem $(15,38 \%)$.

\section{Tabela 4}

Frequência e Percentuais da Citação de Marido e Filhos por Níveis de Proximidade nos Diferentes Campos do Mapa

\begin{tabular}{lccccccccc}
\hline \multicolumn{1}{c}{ Campos } & $\begin{array}{c}\text { Marido } \\
(n=7)\end{array}$ & $\begin{array}{c}\text { Filhos } \\
(n=26)\end{array}$ & Nível & $\begin{array}{c}\text { Marido } \\
(n=7)\end{array}$ & \multicolumn{2}{c}{$\begin{array}{c}\text { Filhos } \\
(n=26)\end{array}$} \\
\cline { 2 - 9 } & $F$ & $\%$ & $F$ & $\%$ & & $F$ & $\%$ & $F$ & $\%$ \\
\hline $\begin{array}{l}\text { Família } \\
\begin{array}{l}\text { Parentes/Vizinhos } \\
\text { e Amigos }\end{array}\end{array}$ & 0 & 0 & 0 & 0 & $2^{\circ}$ & 1 & 14,28 & 7 & 26,92 \\
$\begin{array}{l}\text { Grupo de Trabalho } \\
\text { do Meliponário }\end{array}$ & 2 & 28,57 & 6 & 15,38 & $3^{\circ}$ & 0 & 0 & 5 & 19,23 \\
APAN & 0 & 0 & 0 & 0 & $4^{\circ}$ & 0 & 0 & 3 & 11,38 \\
Outros locais & 2 & 28,57 & 0 & 0 & $5^{\circ}$ & 1 & 14,28 & 1 & 3,84 \\
\hline Total de citação & 11 & & 32 & & & 11 & & 28 & \\
\hline
\end{tabular}

Quanto aos conflitos, observou-se uma maior frequência nos campos da família e do Grupo de Trabalho no Meliponário, conforme a Tabela 5. No que tange aos rompimentos, cons- tatou-se um maior número nos campos dos Parentes/ Vizinhos/ Amigos e Grupo de Trabalho no Meliponário (Tabela 5). 
Tabela 5

Frequência dos Conflitos e Rompimentos. Média de Proximidade

\begin{tabular}{lccccc}
\hline \multirow{2}{*}{ Campos } & \multicolumn{2}{c}{ Conflito } & \multicolumn{2}{c}{ Rompimento } & Proximidade \\
\cline { 2 - 6 } & $F$ & $M$ & $F$ & $M$ & $M$ \\
\hline Família & 6 & 0,86 & 0 & 0 & 0,05 \\
Parentes/ Vizinhos/ Amigos & 2 & 0,28 & 3 & 0,43 & 0,08 \\
Grupo de Trabalho do Meliponário & 6 & 0,86 & 3 & 0,43 & 0,07 \\
APAN & 1 & 0,14 & 0 & 0 & 0,02 \\
Outros locais & 0 & 0 & 0 & 0 & 0,00 \\
Mapa & 15 & & 6 & & 4,77 \\
\hline
\end{tabular}

No campo Família, os conflitos são descritos como brigas cotidianas, e um exemplo é o conflito descrito com os filhos menores: "Teimoso e danado". "Muito mal criado". No entanto, os filhos permanecem no nível 2 da circunferência, caracterizando um alto grau de proximidade no convívio da família.

A análise das relações mais distantes (níveis 3 e 4 da circunferência) das participantes indica alguns contatos marcados por conflitos, apesar de que, em outros campos, as participantes às vezes indicaram a mesma pessoa em campos diferentes, classificando-as nos níveis 1 e 2 da circunferência. As vivencias e atividades desenvolvidas nas relações nos diferentes contextos pode ser a razão pela qual a mesma pessoa é classificada como insatisfatória em um campo e em outro como satisfatório, o que é justificado pelas participantes abaixo.

"Como amiga ela é muito boa, mas no trabalho do meliponário existe algumas desavenças" (Maria das Dores, Junho/2010, Preazinho).

"meninos danados, mas o mais velho me ajuda no meliponário, trabalha direitinho, mas aqui em casa apronta muito" (Andrea, Junho/2010, Marajá).

Por outro lado, os conflitos podem ocorrer pela valorização da privacidade e da autonomia, acarretando dificuldades de convivência ou rompimento da relação, é assim que Claudia caracteriza a relação com a sua sogra:

"pessoa de difícil convivência e se intromete muito na minha vida mais do que meu marido. Eu quero ter a minha vida com ele sem ela intrometer, porque atrapalha muito" (Claudia, Julho/2010, Preazinho).

$E$ ainda esses conflitos podem permanecer e se apresentar em outros campos, como no campo Grupo de Trabalho do Meliponário, em que Claudia se refere outra vez à sogra como:

"uma pessoa dificil de trabalhar junto, não conversa muito, e não se une no grupo de trabalho" (Claudia, Julho/2010, Preazinho). No quinto nível da circunferência, as relações se caracterizam como conflituosas com rompimentos, mas que, em alguns momentos, as pessoas convivem em relações formais, como é justificada:

"Uma relação muito dificil, minha nora é uma pessoa dificil de lidar e no meliponário é o único momento que tenho contato com ela, por isto nem coloquei ela como parente, porque não existe relação, mas a gente trabalha do mesmo jeito, vamos todos para o meliponário" (Adriana, julho/2010, Marajá).

Como pôde ser observado e descrito no diário de campo, as participantes da pesquisa convivem com os parentes que, na sua maioria, moram nas comunidades ou em proximidades. Apesar da boa convivência com os familiares, muito apoio e ajuda mútua, existem conflitos e insatisfações que estão relacionados, na maioria das vezes, às falhas na organização das atividades desenvolvidas no meliponário. No entanto, as famílias estão sempre em contato, por ser uma comunidade pequena e todos se conhecerem. $\mathrm{O}$ 
maior contato ocorre no trabalho do meliponário, como declara Claudia:

"No meliponário todo mundo trabalha junto. Discuti até chegar a um entendimento. Como fazer o serviço, o dia e quem irá fazer. Às vezes tem discussão, alguns não tem compromisso. No inicio tinha uma planilha de dias de trabalho, depois desorganizou tudo, ai dá confusão".

"Sempre que discutimos, depois conversamos para nós entender melhor e o serviço não parar".

A relação dos membros do grupo do Projeto Abelhas Nativas é de união. Apesar disto, as participantes declaram que pode haver eventuais conflitos e divergências com os coordenadores do projeto, segundo uma das participantes da pesquisa:

"Tem a formação da teoria, mas a gente tem a riqueza sobre a ideia e a experiência" (Andrea, Julho/2010, Marajá).

No entanto, as relações das famílias com os coordenadores do Projeto Abelhas Nativas são consideradas positivas. As participantes admitem que as famílias estão sempre em contato com novidades trazidas pelos entidades. Além disso, essas proporcionam muitas melhorias na comunidade com o auxílio nas caixas das abelhas, a hidratação do mel, transporte e o curso de manejo.

\section{Discussão}

As comunidades estudadas se caracterizam por formarem uma grande rede de parentesco, ou seja, todos são de uma mesma família. Portanto, há sempre algum grau de parentesco, seja próximo, como filhos, irmãos, cônjuges, ou mais distante, como tios, avós, cunhados, sobrinhos etc. Com isso, as pessoas que formam os campos de contatos da pesquisa são compostas, na maioria das vezes, por membros da família mais próximos ou por parentes mais distantes, que, por sua vez, também são vizinhos, amigos e trabalham no grupo do meliponário.

As mulheres conseguem articular outros membros da família, como os filhos, e integramse para a execução das atividades no trabalho com as abelhas. Além disso, outras organizações que estão envolvidas no Projeto Abelhas Nativas dão suporte para a realização dessas atividades, como o fornecimento de auxilio técnico e transporte da produção. Como é demonstrado nos resultados, as participantes relatam que o desenvolvimento do Projeto funciona como fator fundamental para a manutenção de uma visão positiva da realidade e a motivação para aspiração de novas conquistas e a melhoria das condições de vida das comunidades.

Outro fato que pode garantir para muitas das mulheres participantes da pesquisa uma melhor atuação é a iniciativa de frequentar o ensino fundamental noturno da comunidade, o que lhes pode possibilitar ter novas aspirações e projetos futuros e uma maior atuação de trabalho em outros contextos.

Contudo, como pode ser verificado a partir do dado de concepção do trabalho e divisão de papeis discutido por Carloto e Mariano (2010) e Romanelli (1986) sobre a atuação das mulheres em atividades rentáveis, como é o caso das mulheres meliponicultoras, não garante a elas uma mudança de valores, símbolos e ideias referente ao papel que representam na família. Elas sempre tentam conciliar a nova atividade ao trabalho doméstico e cuidado com os filhos, apresentando uma nítida representação da divisão sexual do trabalho, em que consideram que o trabalho mais apropriado das mulheres é no cuidado da casa e dos filhos, e dos homens no trabalho da roça, além de participarem de atividades que elas caracterizam como "leves" quando exercem a atividade na lavoura ou no meliponário.

Esse resultado corrobora as pesquisas de Brumer (2004) e Maia (2004), que apontam que essa é uma realidade também em diferentes contextos de agricultura familiar, em que as mulheres são responsáveis pelas atividades domésticas e estão inseridas em outros mercados de trabalho. Além disso, no desempenho de atividades produtivas, nas quais podem mesmo substituir os homens, não é acompanhado do reconhecimento deste como um domínio seu, o que é expresso na noção de "ajuda" que o designa. Ademais, a diferenciação das atividades exercidas pelos membros das famílias descri- 
tas pelas participantes da pesquisa é identificada por K. F. Silva (1999) como um conceito tradicional de trabalho que separa as tarefas masculinas das femininas, classificando-as em: trabalho reprodutivo, que "compreende as atividades domésticas (lavar, cozinhar, cuidar das roupas e dos filhos etc.) ou mesmo todo trabalho ligado à sobrevivência do grupo familiar"; e trabalho produtivo, que designa as atividades que produzem mercadorias e bens, os quais podem ser comercializados e obter ganhos monetários. Além disso, os dados apontam a mulher como a responsável pelo controle do orçamento da família, o que a coloca como a principal gestora do núcleo familiar. Mesmo com pouca renda elas são capazes de garantir o controle e metas dos projetos familiares. $\mathrm{O}$ que se pode verificar é a capacidade da mulher de enfrentar os problemas cotidianos e através das próprias experiências permitindo em sua tarefa proporcionarem uma nova perspectiva aos membros familiares (Biasoli-Alves, 2000).

Os resultados deste estudo são discutidos de forma a integrar os dados do M5C (Samuelsson et al., 1996, adaptado por Hoppe, 1998), da entrevista semiestruturada, do DC e da literatura, enfatizando os campos Grupo de Trabalho do Meliponário, Parentes/Vizinhos/Amigos, Família e Associação do Projeto de Abelhas Nativas. Esses contextos destacaram-se na análise dos resultados por corresponderem tanto aos campos com o maior número de pessoas quanto aos campos que apresentam contatos mais próximos e com qualidade, além de principais fornecedores de apoio.

Especificamente, os campos Família, Parentes/Vizinhos/Amigos e Grupo de Trabalho do Meliponário destacam-se por apresentar um maior número de pessoas e de vínculos mais próximos e de maior qualidade. De fato, demonstra que em comunidades isoladas, como as que são apresentadas nas comunidades do Nordeste do Maranhão, é muito provável que quase todos guardem entre si laços de parentesco e fortes laços de amizade e cooperação. $\mathrm{O}$ isolamento e os laços estreitos destas famílias podem ser comparados às populações ribeirinhas, onde o rio é o que ao mesmo tempo cria vínculos e isolamen- tos entre as pessoas dessas populações, também pode ter uma maior frequência de interação entre os membros familiares. Criando, assim, trajetórias de desenvolvimento tipicamente adaptadas a este modo de vida (Mendes et al., 2008; S. S. C. Silva, 2006).

Sendo assim, como uma forma de estratégia de sobrevivência, o grande numero de contatos com grande proximidade das famílias, grupos de parentes, vizinhos e amigos constituem a principal fonte de apoio social para as mulheres dessas comunidades. Esses resultados vão ao encontro com as ideias de Durham (1983), que entende a família como uma unidade de reprodução social e biológica, e simultaneamente, como um grupo de cooperação econômica e de consumo coletivo de bens materiais e simbólicos.

Os dados apresentam ainda, o maior número de contatos no Grupo de Trabalho do Meliponário, o que demonstra ser uma atividade importante para a agregação de apoio social e afetivo das famílias estudadas. Ainda assim, no caso dessas participantes, em especial o meliponário também é fonte de fortes vínculos. É evidente que para essas mulheres o grupo do meliponário funciona como fonte de novas relações, ampliando as suas redes de apoio. Destaca-se também o fato que nesse grupo há o maior numero de contatos satisfatórios. Esse resultado sugere a evidencia da construção de redes sociais, enfatizado por Sluzki (1996) que identifica o princípio da reciprocidade como um dos elementos-chave para a compreensão do complexo processo de pertencimento a uma rede de parentesco e vizinhança. Na prática, se constitui na redistribuição de papéis e na agregação de membros originalmente não pertencentes à família. Relacionando, segundo Atneave e Ross (1982), os diversos papéis que cada um desempenha e/ou assume na relação. Adicionalmente, o estudo de Sarti (2007), sobre famílias e redes de parentesco indicou, também, que a construção as redes sociais incluem os membros familiares a novas atribuições e funções nos contextos inseridos. Demonstrando que essas mudanças constituem uma busca pela família por soluções para sua manutenção, adaptando sua estrutura ao seu contexto sócio-histórico. 
Os resultados demonstram que, para a manutenção dessas redes de apoio, as participantes mantêm vínculos nos vários campos e estão classificados em vários níveis de proximidade. Em relação à qualidade dos vínculos, ou seja, a colocação das pessoas nos círculos adjacentes ao centro mostra que as mulheres participantes da pesquisa se concentram, na sua maioria, no primeiro e segundo níveis, demonstrando que as relações mantidas são de grande proximidade, relações de trocas e as retribuições subsequentes. Esse aspecto pode ter como efeito que, com a existência desse estreitamento das relações com a família, rede de vizinhança, parentes e grupo de trabalho no meliponário, as mulheres das comunidades possam participar mais ativamente da vida familiar cotidiana. Toda essa articulação mantida pelas mulheres é discutido também por Durham (1973) e Fausto-Neto (1982), revelando a mulher como a grande articuladora e mantenedora das relações com vizinhos e parentes. Nos resultados, pode-se identificar a relação de parceria entre as famílias no trabalho no meliponário. Apesar de haver uma divisão das colmeias por famílias, o cuidado e o manejo com todas as colmeias ocorrem de forma conjunta, bem como a divisão da produção também é dividida com todas as famílias de forma igualitária, independente de a produção ter ocorrido de forma desigual entre as colmeias das várias famílias. Pode-se supor que como efeito sistêmico desse arranjo essas famílias investem umas nas outras, as redes sociais acabam se mantendo por meio de várias estratégias e articulações que garantem a sobrevivência integrada de todas. Como podese verificar nos dados da entrevista semiestruturada, esses vínculos criam laços de amizade que se solidificam, o que S. S. C. Silva et al., (2010) apresentam como condicionamento à formação de vínculos na rede social que asseguram a proteção de todos os membros familiares e geram novos vínculos que podem ser utilizados em situações de dificuldades.

Outro resultado que se apresenta nas relações, de trabalho e da família é a ocorrência de repetidas citações dos maridos e dos filhos como fontes de apoio em vários campos, principalmente o campo do Grupo de Trabalho do Meli- ponário, e cujos contatos são mais satisfatórios e próximos. Além do campo da família, o campo do Grupo de Trabalho no Meliponário e Outros Locais foram os que se destacaram constatando uma valorização destes membros nesta rede de relações. Esses resultados mostram uma intima relação família-trabalho na articulação de seus membros para a atividade produtiva remunerada e na sua organização para garantir a sobrevivência imediata e buscar melhores condições de vida.

Todos esses fatores que são constituídos nas redes de apoio social dão sustentabilidade ao desenvolvimento de atividade da meliponicultura - criação de abelhas indígenas sem ferrão - pois é necessário que a família mantenha as interações internas, que participe de diferentes subsistemas familiares, contextos e de grupos extrafamiliares. Portanto, esses aglomerados familiares mantêm-se unidos não apenas por uma questão afetiva, mas, também, por uma questão de dependência mútua para sobreviverem. Essa dependência é definida por Meneses (2007) como fator fundamental na determinação das funções de apoio, manutenção e sobrevivência dos membros da família e da comunidade.

O contexto relacionado ao campo da APAN apresentou-se com baixo número de pessoas nos níveis do campo. Essa associação foi criada recentemente e por esse motivo os vínculos ainda estão se estruturando. As mulheres relataram também que encontram dificuldades para se inserirem em movimentos que vão além dos limites das comunidades, pois o acesso à sede da associação, que fica no município de Urbano Santos/MA, é dificultado pela distância e as péssimas condições das estradas e transportes. Além disso, as mulheres participantes da pesquisa apresentam baixa escolaridade, o que restringe a atuação em atividades formais, como a participação em cursos de capacitação e atividades formais e burocráticas na associação. Apesar de toda a dificuldade encontrada, os conhecimentos adquiridos nos cursos realizados no município de Urbano Santos/MA são transferidos às mulheres das comunidades por meio dos mediadores, na maioria das vezes, formados por homens. Esses por sua vez, assumem um papel importan- 
te de integrar as famílias da comunidade e levar os conhecimentos adquiridos às mulheres que executam a atividade. Essa mediação possibilita a inclusão das mulheres no processo e no desenvolvimento da atividade da meliponicultura.

Outro resultado importante refere-se à baixa citação das relações constatada no campo Outros Locais. Esse campo pode representar mais um ambiente, onde a participante também desenvolve atividades e interage com outras pessoas, as quais não estão inseridas nos demais campos do instrumento. As participantes mencionaram a igreja como o único local que frequentam na comunidade, além dos outros campos que constam no mapa. No presente estudo, a baixa frequência ou a ausência de pessoas no campo Outros Locais pode indicar a pouca opção que essas mulheres têm de convivência nas comunidades e devido ao isolamento das mesmas.

Por outro lado, os dados demonstram também a existência, mesmo que menor, de qualidade dos vínculos nos níveis de proximidade: o terceiro e quarto níveis correspondem às relações mais distantes, e o último nível (periférico) representa os contatos insatisfatórios e com rompimento. Os conflitos se concentram onde também tem mais intensidade de contatos, ou seja, onde a rede é mais intensa, no campo Grupo de Trabalho do Meliponário e no campo Família, o que pode ser explicado pela intensidade das redes de apoio, pois isso pode gerar conflitos e insatisfações. Esses dados estão em consonância com as considerações de Romanelli (1995) para quem, na família, a manifestação de aspirações, sentimentos e emoções são mais livres do que no domínio público, o que contribui para que a vida doméstica seja carregada de tensões e conflitos.

Tais conflitos e insatisfações apresentados nos resultados estão relacionados, na maioria das vezes, às falhas na organização das atividades desenvolvidas no meliponário e à deficiência dos cursos de capacitação para as mulheres da comunidade. Todas as reivindicações podem levar ao conflito entre alguns membros do Grupo de Trabalho do Meliponário, já que as mulheres atuam diretamente nas suas atividades e, em alguns momentos, podem reivindicar a participa- ção de todos e um maior investimento em suas capacitações. Além disso, pode-se descrever que as insatisfações e os conflitos relatados nas redes das mulheres estudadas, mesmo no local de trabalho (Grupo de Trabalho do Meliponário) e as relações com vizinhos, parentes e amigos das comunidades apresentam uma conotação mais livre e emocional, pois se trata de contatos familiares próximos. Apesar das redes do Grupo de trabalho do Meliponário e de vizinhos, parentes e amigos, maioria das vezes, serem nas mesmas pessoas, as mulheres conseguem fazer uma distinção dos papeis para que não haja interferências no desenvolvimento do trabalho, ou para que as diferenças de ideias no trabalho não atrapalhe a relação familiar ou de amizade.

Outro aspecto que deve ser levado em conta é que apesar de a rede de relações com vizinhos e parentes ser importante na vida das famílias, seus integrantes também valorizam a autonomia e a privacidade. Porém, quando a autonomia e a privacidade são quebradas, quase sempre ocorre um rompimento dessas relações, gerando, assim, conflitos entre vizinhos e parentes (C. C. Macedo, 1979). No entanto, a família, bem como os membros das comunidades estudadas, forma um grupo de convivência e uma unidade de cooperação econômica e de consumo material e simbólico, mantida para enfrentar as dificuldades impostas pelo cotidiano e para alcançar determinados objetivos no futuro. Além disso, empenho e dedicação das mulheres ao trabalho no meliponário e nas relações familiares são fatores fundamentais para que tais conflitos sejam amenizados.

\section{Considerações Finais}

Os dados levantados permitiram constatar a importância da rede de apoio social das mulheres investigadas para o desenvolvimento da atividade da meliponicultura, criando eixos de inserção dessas mulheres em vários contextos e níveis de relacionamento. A Família, os Parentes/Vizinhos/Amigos e o Grupo de Trabalho do Meliponário foram mencionados por essas mulheres de forma a caracterizar uma intensa rede de apoio social. Esse dado remete à vinculação existente 
entre as mulheres e uma rede de parentesco, que estão presentes em todos os campos estudados, e que são importantes para o desenvolvimento da atividade, comumente, da comunidade e das pessoas envolvidas.

Por meio das contribuições no trabalho remunerado no meliponário e das atividades domésticas, as mulheres atuam de uma forma decisiva no desenvolvimento de ações nas comunidades. Apesar de considerarem o trabalho que exercem como uma "ajuda", com uma percepção menor de sua contribuição na execução da atividade da meliponicultura, o trabalho delas é de fundamental importância para a manutenção e o desenvolvimento da atividade.

A procura de outras saídas para os momentos difíceis da vida cotidiana faz com que as mulheres sejam levadas a se deslocar do âmbito doméstico para o público, organizando-se e, inclusive, participando de ações coletivas. Além disso, este estudo demonstrou que uma rede de apoio social permite às mulheres a circulação em vários contextos, bem como a interação entre as pessoas de outros microssistemas de modo adaptado e com equilíbrio nas relações de poder e pode proporcionar a possibilidade de terem sucesso na execução das atividades da meliponicultura. Essas experiências implicam transformações do âmbito doméstico e criam novas condições para a presença feminina nos movimentos sociais, estabelecendo, assim, a integração do cenário público e o privado, o que contribui para processos de transformações macrossociais. Contudo, apesar de a comunidade se beneficiar das intervenções de várias instituições, conhecimentos e difusões de novas tecnologias, tais famílias ainda permanecem em um contexto de empobrecimento econômico local e em vulnerabilidade social.

A despeito da limitação na quantidade de participantes - um reflexo das características da população estudada -, para fins de ter uma melhor perspectiva de gênero e de subsistemas familiar, trabalhos futuros poderiam comparar as redes e percepções das mulheres com o dos seus esposos e filhos. Aconselha-se também investigar outros arranjos de sobrevivência familiares.
Entende-se por fim que esse trabalho pode ser útil para a compreensão dos efeitos de políticas públicas, visto que pode-se pensar as relações entre as redes de apoio social e a participação das mulheres nas atividades envolvidas, que explorem os diversos aspectos desses relacionamentos. Essas análises poderiam contribuir para uma maior compreensão da participação das mulheres na formação da rede de apoio, apontando para uma proposta com bases democráticas e sustentáveis do desenvolvimento da meliponicultura.

\section{Referências}

Associação Maranhense para a Conservação da Natureza. (2005). Boletim do Projeto Abelhas Nativas (São Luís), 12. Recuperado em 10 de agosto de 2010, de http://www.projetoabelhasnativas. org/

Atneave, R., \& Ross, S. (1982). Redes familiares. Buenos Aires, Argentina: Amorrortu editores.

Biasoli-Alves, Z. M. M. (2000). Continuidades e rupturas no papel da mulher brasileira no século XX. Psicologia: Teoria e Pesquisa, 16(3), 233239.

Brito, F. S. (2008). Mulher chefe de família: Um estudo de gênero sobre a família monoparental feminina. Revista Urutágua, 15, 42-52.

Brito, R., \& Koller, S. H. (1999). Desenvolvimento humano e redes de apoio social e afetivo. In A. M. Carvalho (Org.), O mundo social da criança: Natureza e cultura em ação (pp. 115-29). São Paulo, SP: Casa do Psicólogo.

Bronfenbrenner, U. (1996). A ecologia do desenvolvimento humano: Experimentos naturais e planejados. Porto Alegre, RS: Artes Médicas. (Trabalho original publicado em 1979)

Brumer, A. (2004). Gênero e agricultura: A situação da mulher na agricultura do Rio Grande do Sul. Revista Estudos Feministas, 12(1), 205-227.

Bruschini, C. (1994). O trabalho da mulher no Brasil: Tendências recentes. In H. Saffioti \& M. MunõzVargas (Orgs.), Mulher brasileira é assim (pp. 63-93). Rio de Janeiro, RJ: Rosa dos Tempos.

Bruschini, C. (2007). Trabalho e gênero no Brasil nos últimos dez anos. Cadernos de Pesquisa, $37(32), 537-572$. 
Carloto, C. M., \& Mariano, S. A. (2010). No meio do caminho entre o privado e o público: Um debate sobre o papel das mulheres na política de assistência social. Revista Estudos Feministas, 18(2), 451-471.

Durham, E. R. (1973). A caminho da cidade. São Paulo, SP: Perspectiva.

Durham, E. R. (1983). Família e reprodução humana. In E. R. Durham, B. Franchetto, M. L. V. C. Cavalcanti, \& M. L. Heilborn (Orgs.), Perspectivas antropológicas da mulher (Vol. 3, pp. 13-44). Rio de Janeiro, RJ: Zahar.

Elkaim, M. (1989). Las prácticas de la terapia de red. Madrid, España: Gedisa.

Fausto-Neto, A. M. Q. (1982). Família operária e reprodução da força de trabalho. Petrópolis, RJ: Vozes.

Ferraz, M. C. (1992). A arquitetura rural na Serra da Mantiqueira. São Paulo, SP: Empresa das Artes.

Fleck, A., \& Wagner, A. (2003). A mulher como a principal provedora do sustento econômico familiar [Edição especial]. Psicologia em Estudo (Maringá), 8, 31-38.

Fonseca, C. (1987). Aliados e rivais na família: O conflito entre consanguíneos e afins em uma vila Porto-Alegrense. Revista Brasileira de Ciências Sociais, 2(4), 88-104.

Garmezy, N., \& Masten, A. (1994). Chronic adversities. In M. Rutter, E. Taylor, \& L. Herson (Orgs.), Child and adolescent psychiatry (pp. 191-207). Oxford, UK: Blackwell.

Hoppe, M. (1998). Redes de apoio social e afetivo de crianças em situação de risco (Dissertação de mestrado em Psicologia do Desenvolvimento, Universidade Federal do Rio Grande do Sul, Porto Alegre, RS, Brasil).

Instituto Brasileiro de Geografia e Estatística. (2000). Sinopse preliminar do censo demográfico. Rio de Janeiro, RJ: Autor.

Macedo, C. C. (1979). A reprodução da desigualdade. São Paulo, SP: Hucitec.

Macedo, M. dos S. (2001). Tecendo o fio e segurando as pontas: Mulheres chefes de família em Salvador. In C. Bruschini \& C. R. Pinto (Orgs.), Tempos e lugares de gênero (pp. 57-70). São Paulo, SP: Editora 34.

Maia, C. J. (2004). Trabalho, família e gênero: Estratégias de reprodução social camponesa no médio Jequitinhonha. Mulher e Trabalho, 4, 89-103.
Marteleto, R. M., \& Silva, A. B. O. (2004). Redes e capital social: $\mathrm{O}$ enfoque da informação para o desenvolvimento local. Ciência da Informação, 33(3), 41-49.

Mendes, L. S. A., Pontes, F. A. R., Silva, S. S. C., Bucher-Maluschke, J. S. N. F., Reis, D. C., \& Silva, S. D. B. (2008). Inserção ecológica no contexto de uma comunidade ribeirinha amazônica. Revista Interamericana de Psicología, 42(1), 1-10.

Meneses, M. P. R. (2007). Redes sociais - pessoais: Conceitos, práticas e metodologia (Tese de doutorado, Faculdade de Psicologia, Programa de Pós-Graduação em Psicologia, Pontifícia Universidade Católica do Rio Grande do Sul, Porto Alegre, RS, Brasil).

Meneses, M. P. R., \& Sarriera, J. C. (2005). Redes sociais na investigação psicossocial. Aletheia, 21, 53-67.

Oliveira, Z. L. C. (1990). Crisis, situación familiar y trabajo urbano. In N. Aguiar (Org.), Mujer y crisis (pp. 55-74). Venezuela: Nueva Sociedad.

Romanelli, G. (1986). Famílias de camadas médias. A trajetória da modernidade (Tese de doutorado em Antropologia, Faculdade de Filosofia, Letras e Ciências Humanas, Universidade de São Paulo, SP, Brasil).

Romanelli, G. (1995). Autoridade e poder na família. In M. do C. B. de Carvalho (Org.), A família contemporânea em debate (pp. 73-88). São Paulo, SP: Cortez.

Rubio, J. M. I., \& Devillard, M. J. (2001). Prácticas de Antropología Social. Material didáctico. Madrid, España: Universidad Complutense de Madrid.

Samuelsson, M., Thernlund, G., \& Ringstrom, J. (1996). Using the five map to describe the social network of children: A methodological study. International Journal Behavioral Development, 19, 327-345.

Sarti, C. A. (2007). A familia como espelho: Um estudo sobre a moral dos pobres (4. ed.). São Paulo, SP: Cortez.

Silva, K. F. (1999). Repensando o trabalho feminino no meio rural. In M. Ferreira (Org.), Mulher, gênero e políticas públicas. Salvador, BA: Redor.

Silva, S. S. C. (2006). Estrutura e dinâmica das relações familiares de uma comunidade ribeirinha da região amazônica (Tese de doutorado, Instituto de Psicologia, Universidade de Brasília, DF, Brasil). 
Silva, S. S. C., Pontes, F. A. R., Lima, L. C., \& Bucher-Maluschke, J. B. (2010). Rede social e papéis de gênero de casais ribeirinhos de uma comunidade amazônica. Psicologia: Teoria e Pesquisa, 26(4), 605-612.

Siqueira, A. C., Betts, M. K., \& Dell'Aglio, D. D. (2006). A rede de apoio social e afetivo de adolescentes institucionalizados no Sul do Brasil. Revista Interamericana de Psicología, 40(2), 149-158.

Sluzki, C. (1996). La red social: fronteras de lapráctica sistémica. Barcelona, España: Gedisa.
Szymanski, H. G. (2002). Viver em família como experiência de cuidado mútuo: Desafios de um mundo em mudança. Revista Serviço Social e Sociedade, 71, 9-25.
Recebido: $23 / 10 / 2012$

$1^{a}$ revisão: 09/01/2013

$2^{a}$ revisão: $14 / 02 / 2013$

Aceite final: 25/02/2013 